\title{
Into the unknown
}

Cite as: CMAJ 2020 May 19;192:E564-5. doi: 10.1503/cmaj.1095869

Posted on cmajnews.com on May 1, 2020

rovinces and territories are starting to reopen businesses and other services as new cases of coronavirus disease 2019 (COVID-19) appear to have peaked. Ramping up testing is an essential part of many of these plans, but governments continue to struggle to meet promised targets. Meanwhile, Quebec's decision to reopen schools has been controversial, especially given concern about COVID-19-related inflammatory symptoms in kids and recent reports that children may be just as infectious as adults.

To put these developments in context, CMAJ reached out to infectious disease specialists Dr. Srinivas Murthy of BC Children's Hospital and the University of British Columbia in Vancouver, Dr. Matthew Oughton of the Jewish General Hospital and McGill University in Montreal, and Dr. Alon Vaisman of the University Health Network in Toronto.

\section{CMAJ: What recent developments in}

Canada's pandemic response are most promising and what are most

\section{concerning?}

Oughton: The most promising sign in recent days has been the indication that the curves of new cases are flattening in many provinces. Flattening these curves is a necessary first step, but not the last, before mitigation measures can be safely relaxed. [However,] remote communities, including First Nations reservations, are beginning to report index cases and some outbreaks. Given the chronic infrastructure problems that exist in many communities... rapid spread of disease may occur, with limited capacity to handle the more severe cases.

Vaisman: On the acute care side, numbers of admissions have been stabilizing or already peaked. The overall system hasn't been overwhelmed to the point where we're not able to provide critical care for patients. The capacity of most hospitals remains high.

Murthy: It's going to be fascinating to watch over the coming weeks as 10 different provinces have 10 different approaches to reopening and seeing how things work out. Is now the right time to reopen? No one can know. the ability to respond quickly. It makes sense to have a step-wise plan that begins with removal of some restrictions in lowrisk populations but that absolutely must be accompanied by vigilant monitoring of those populations, availability of facilities and reagents to quickly test those populations, capacity to perform rapid contact tracing and the ability of local health care facilities to assess people if

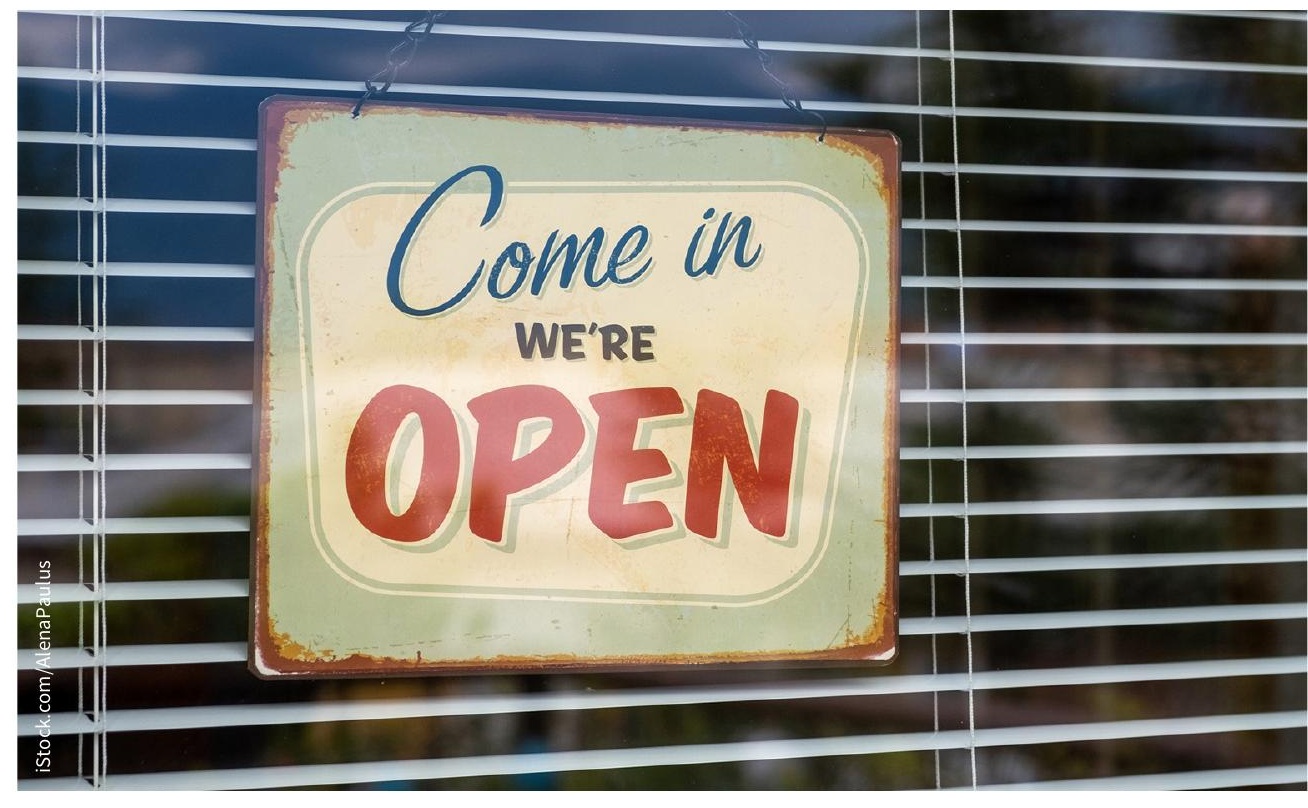

Questions remain about Canada's testing capacity as provinces prepare to ease pandemic restrictions.

CMAJ: What do you think about the different strategies the provinces are taking to reopen? What restrictions can we safely lift first?

Oughton: Relaxing some of the mitigation measures while SARS-CoV-2 is still circulating in a largely non-immune population is rather like walking into the forest to gather firewood while wolves are nearby; it must be done cautiously, with vigilant monitoring everywhere and new disease arises. All these factors, not just some, must be in place before restrictions are relaxed.

Vaisman: With no vaccine and a lack of clarity around herd immunity I do wonder what the end game is. Long-term care outbreaks have to be dealt with before things open up, because if there's ongoing transmission in those settings you're always going to have, in the background, the chance of an epidemic 
[resurgence]. Any work setting where you can't social distance are the ones that shouldn't be opened, but areas where you can, like a factory in a remote setting where people drive in and wear PPE already, that makes sense to reopen.

Murthy: Everyone has competing interests in this and policy makers are struggling to figure out the best approach because the science is not there to guide them. Over the past few weeks we've said groceries and health care are essential to remain open, and now education and expanding health care infrastructure seems to be the next things that would be important to re-institute. ... l'd like to see new case counts go down faster than they have. When you look at Canada-wide numbers they seem too flat to me, although that may be a factor of increased testing capability.

CMAJ: How has our understanding about children and COVID-19 evolved since the beginning of the pandemic and how does that complicate plans to reopen schools?

Murthy: There are all sorts of conflicting data out there about COVID-19 disease and children and whether they're vectors for transmission. Some modelling studies say you ignore the kids, they're irrelevant. Other studies have found children have substantial viral load. Anyone who says it's definitively one way or the other is incorrect and we'll have to figure this out as we go forward. Ideally, we'll collect detailed data on how things play out in different regions with good communitylevel tracing of kids and their families.

Vaisman: We know that children carry numerous respiratory infections and we know they carry them for longer than an adult will, so the same may be true with COVID-19. How that affects the rest of the population is hard to know at this point because children are rarely swabbed, they rarely have symptoms. We may get an answer soon based on clusters developing in Canada and other countries.

Oughton: Until we have more robust data, any reopening must be done with an abundance of caution, and school attendance should remain voluntary in order to protect students and school staff who may be at high risk of acquiring COVID-19 or having severe complications from it.

\section{CMAJ: What should our testing} capacity be and what will be required to meet that standard?

Murthy: Scientists are of varying viewpoints on the target number of tests to comfortably reopen. There are some American folks who say that every single person should be tested every two weeks and that's the only way, and there are others who say it should be based on symptoms or a link to an ongoing outbreak. Probably somewhere in the middle is the right spot.

Oughton: Dr. Theresa Tam recently stated a federal target of 60000 tests per day, and present performance is only about one-third of that. The major challenge for Canada is that most of our tests are RT-PCR [reverse transcription polymerase chain reaction], which requires reagents and swabs for which we are in competition with countries around the world. We need better domestic capacity to manufacture these reagents, as well as other diagnostic assays, including accurate and affordable point-ofcare tests for remote areas.

Vaisman: More important than looking at the number of tests is looking at the number of people who need a test. If you're still turning away people who are mildly symptomatic, or folks in longterm care facilities are not getting swabbed, or there are remote villages and reserves that don't have timely access, then you know the number of tests you're doing is not enough. You can do all the tests you want without making a dent in the problem if you're not testing the right people.

\section{CMAJ: Given that Canada has been}

locked down for weeks, why are we

still seeing so many new cases

reported?

Vaisman: Intuitively, it doesn't make sense, but there's a huge delay that occurs because [the virus has] already burned through the population, and people who never had symptoms - which we're understanding now is probably a good chunk of them - are transmitting the virus without even knowing it, and now it's made its way to people who are showing symptoms. And then there's probably a lack of proper social distancing going on.

Murthy: There are a lot of people who do not have the capacity to isolate themselves. The bulk of cases and deaths have been in places where people are unable to avoid contact with others, specifically jails, meat-processing plants and longterm care facilities.

Oughton: COVID-19 seems to be affecting different segments of our population over time. In March, most cases were travel-associated, often in patients with the relative youth and health required for most travel. In April, the affected population became older with multiple medical comorbidities, reflecting the devastation this disease has caused in long-term care facilities that were vulnerable due to chronic understaffing and underpreparation. I am concerned that May will be the month that our Indigenous populations become increasingly affected; housing and medical facilities [on reserves] are vulnerable in many of the same ways that our long-term care facilities are.

\section{Lauren Vogel, CMAJ}

